\title{
CAPITAL SOCIAL, SATISFAÇÃO E AS DIFERENTES FORMAS DE PARTICIPAÇÃO POLÍTICA
}

Douglas Santos Alves

Simone Viscarra

\begin{abstract}
Resumo
A proposta deste artigo é analisar as atuais mudanças referentes às formas de participação da população em relação à satisfação de necessidades básicas fornecidas pelo Estado e da presença de Capital Social entre os habitantes da cidade de Porto Alegre. Nos últimos anos tem se observado, na cidade, uma crescente importância dos cidadãos em relação à sua atuação na política, ao mesmo tempo em que a forma convencional (regulada e assegurada por leis) diminui. Nosso objetivo é traçar como essas formas de participação estão incidindo na esfera pública, assim como explicar a causa desse deslocamento dos cidadãos a uma participação não convencional.
\end{abstract}

Palavras-chaves: Participação Política; Capital Social; Satisfação Social.

\begin{abstract}
The main objective of this article is to examine the changes in the population political participation in Porto Alegre in the dimension of satisfaction about the basic needs by the State, as well as, the presence of social capital among the citizens. The last years have shown a growing importance of citizens political behavior, at the same time that their involvement in conventional activities has diminished. We seek to examine how these forms of participation are affecting the public sphere, we also seek to explain the reasons as to why the citizens are migrating to a non-conventional participation.
\end{abstract}

Keywords: Political Participation; Social Capital; Social Satisfaction.

A proposta do artigo é analisar a relação que se estabelece entre a satisfação das pessoas com as instituições políticas e sociais associadas ao regime democrático por meio de variáveis de capital social e participação política dos habitantes da cidade de Porto Alegre. Tal relação é avaliada dentro do contexto de distanciamento das pessoas da esfera política, fenômeno marcante das sociedades latino-americanas nas últimas décadas. 0 objetivo principal é averiguar como a participação dos moradores da cidade se caracteriza, se existem diferentes formas de participação e como conceitos provenientes da teoria culturalista, como o de capital social, podem auxiliar na compreensão desses. Em segundo momento, a participação das pessoas será dividida em três categorias: alta, média e baixa, assim aprofundando a análise.

Para atingir o proposto, o conceito de participação política será dividido em três formas: convencional, não convencional e comunitária. Cada uma 
dessas formas será problematizada de acordo com sua relação com as variáveis indicativas de capital social e variáveis demográficas como gênero e escolaridade.

Em termos analíticos serão utilizados os dados empíricos provenientes da pesquisa realizada pelo Núcleo de Pesquisa sobre América Latina (NUPESAL), intitulada: Capital social e desenvolvimento sustentável na formação da cidadania e da qualidade de vida: estudo comparado entre cidades do Brasil, Chile e Uruguai ${ }^{1}$. A amostra do survey foi calculada com base nos parâmetros de sexo, idade e escolaridade fornecidos pelo IBGE no ano 2000, sendo os entrevistados maiores de 16 anos de idade, residentes nessa cidade. Adicionalmente a esses dados também serão analisados os resultados de pesquisas eleitorais realizadas pelo NUPERGS ${ }^{2}$ desde a década de 1960.

A justificativa para se agregar os resultados das pesquisas eleitorais produzidas pelo NUPERGS entre 1960 e 2004 se deve ao fato desses incluírem em seu escopo questões sobre a participação política, confiança institucional e interpessoal dos entrevistados e possuírem uma amostra paramétrica em todas as surveys. Desse modo, permite-se completar os dados de $2005^{3}$.

A sociedade contemporânea está marcada pelas profundas transformações ocorridas no âmbito tecnológico e seus respectivos efeitos sobre o universo das relações de trabalho. A estas se pode agregar as significativas mudanças na estrutura do Estado juntamente com seus desdobramentos sobre direitos e garantias sociais da população, decorrentes das medidas de ajuste econômico ditadas pelo modelo econômico neoliberal. Tal realidade promoveu o aumento de mazelas sociais como pobreza, violência e exclusão, incidindo significativamente nas relações sociais (PNUD, 2004). Isso se demonstrou no fato do desempenho econômico da América Latina na década de 1990 ser inferior ao da década anterior, considerada década perdida.

No âmbito da cultura política, diversos estudos têm apontado, como conseqüência desse processo, uma significativa queda da confiança interpessoal, o isolamento dos indivíduos e a fragmentação de redes sociais como família, amigos e vizinhança. Da mesma forma, uma maior desconfiança institucional, expressa pela apatia e indiferença com relação à política, bem como no aumento da procura de alternativas individuais para problemas coletivos. De tal forma, é possível constatar, tal como sugere Baquero, que:

\footnotetext{
${ }^{1}$ Essa pesquisa contou com o apoio do CNPq em todas as suas etapas.

2 Núcleo de Pesquisa e Documentação da Política Rio-Grandense (Universidade Federal do Rio Grande do Sul). Maiores informações em: <http://www.ufrgs.br/cienciapolitica/pesquisa/nucleosde-pesquisa/nupergs $>$.

${ }^{3}$ A última pesquisa do NUPESAL sobre cultura política e participação em Porto Alegre foi realizada no ano de 2005.
} 


\begin{abstract}
A igualdade de oportunidades está marcadamente ausente na medida em que transforma os cidadãos em consumidores. Assim, a lógica do mercado faz com que as pessoas se comportem de forma egoísta numa orientação comportamental do salve-se quem puder. Essa lógica evidentemente fragiliza os laços sociais e compromete 0 conceito de cidadania (BAQUERO, 2009, p. 16).
\end{abstract}

O debate sobre ação coletiva e vivência comunitária permeia a ciência política desde clássicos como Hobbes, Locke, Rousseau e Tocqueville. Esse último, em sua obra A Democracia na América (1977), já falava da importância da participação para o funcionamento e permanência da democracia nos Estados Unidos, que seria fruto da capacidade da convivência comunitária, de associações livres, ressaltando aspectos como a igualdade das relações sociais facilitando as ações do poder do Estado. No século XX e meados do XXI, o debate sobre associativismo, participação e desempenho democrático ganha novo fôlego (PATEMAN, 1992; AVRITZER, 1997; AVELAR e CINTRA, 2007). Contudo, é nos estudos sobre cultura política que esta discussão, mais precisamente em torno dos recentes debates sobre o conceito de capital social, ganha forma.

O conceito aqui trabalhado, capital social, tem sua origem nos estudos de Putnam (1993) sobre o desenvolvimento democrático na Itália, comparando o desempenho entre norte e sul do país a partir de variáveis como confiança institucional e interpessoal. Contudo, é sua adaptação para a realidade latino-americana que nos interessa, sendo Baquero (2001 e 2003), o autor que agrega ao referencial de Putnam as características que marcam a formação da cultura política da região. Além desses autores, existe ainda um amplo debate travado por teóricos como Coleman (1990), Fukuyama (1996), Durlauf (2004), entre outros.

Para esses autores, capital social está ligado às condições necessárias para a criação de redes de relações que visem melhorar a reciprocidade entre os cidadãos, de forma a que esses possam alcançar os seus objetivos de maneira coletiva. Coleman vincula o capital social ao capital econômico, uma vez que o primeiro inclui aspectos ligados à renda e à riqueza material que determinam o acesso aos bens e serviços daí decorrentes. Trabalhando com o conceito no plano individual, o autor aponta a capacidade de relacionamento do indivíduo baseada em expectativas de reciprocidade e comportamento confiáveis. No plano coletivo, ajudaria a manter a coesão social pela obediência às normas e leis, o que resultaria em uma convivência baseada na associação espontânea, no comportamento cívico, enfim, numa sociedade mais coesa e democrática. Assim, capital social seria o resultado da interação dos atores dentro de uma estrutura permeada por confiança e cooperação, ou seja, o efeito decorrente da interação.

Putnam, por sua vez, afirma que o grau de capital social estaria refletido no grau de confiança, normas, leis, redes de trabalho entre outros, 
que venham a aumentar a eficiência da sociedade. Na sua obra, Making Democracy Work (1993), o autor procura esclarecer as razões pelas quais algumas províncias italianas tinham um desempenho democrático diferenciado e se todas possuíam as mesmas instituições e formatos. Assim, encontrou nas variáveis sócio-culturais e econômicas os elementos que explicavam tal disparidade regional. O conceito de capital social, para ele, remete às "[...] características da organização social, como confiança, normas e sistemas, que contribuam para aumentar a eficiência da sociedade, facilitando as ações coordenadas [...]" (PUTNAM, 1993, p. 302). Dessa maneira, o capital social é definido por um conjunto de fatores interrelacionados: confiança, normas de coesão social, reciprocidade e participação.

Outro autor de importante contribuição sobre o tema é Fukuyama (1996). Para ele:

Social capital can be defined simply as the existence of a
certain set of informal rules or norms shared among members
of a group that permits cooperation among them. The sharing
of values and norms does not itself produces social capital,
because the values may be the wrong ones [...] the norms
that produce capital social must be substantively include
virtues like truth-telling, the meeting of obligation and
reciprocity (p. 378-379) ${ }^{4}$.

$\mathrm{Na}$ tentativa de sintetizar esse debate, Durlauf (2004), afirma que capital social é algo positivo no sentido que colabora com a criação de uma rede de relações entre os indivíduos, por meio de normas, identidades e obrigações de grupos dentro de uma sociedade. Entendendo normas e valores comuns como algo que faz parte da consciência coletiva de um grupo.

De acordo com o debate apresentado, observa-se que o conceito de capital social está em diálogo profundo com a noção de participação política. Contrariando o entendimento majoritário acerca da participação, entendemos que a entrada em cena de camadas mais amplas da população gera uma repercussão positiva sobre o funcionamento da democracia, abrindo possibilidades para mudanças e aperfeiçoamentos do sistema político. Embora boa parte da leitura produzida sobre o assunto ainda se apóie, de forma mais ou menos explícita, na interpretação de Huntington (1968). Segundo essa leitura, a participação de camadas mais amplas da população levaria os sistemas políticos à instabilidade e à crise, sendo, portanto, indesejável. As mudanças e transformações deveriam ocorrer sob o imperativo da ordem e

\footnotetext{
${ }^{4}$ Fukuyama: "capital social pode ser definido como a existência de um conjunto informal de regras ou normas entre membros de um grupo que permite a cooperação dos mesmos. Essa divisão de normas e valores por si mesma não produz capital social, por que os valores podem ser os errados[...] as normas que produzem capital social devem incluir virtudes como a verdade, o encontro entre obrigação e reciprocidade" (Tradução livre de Simone Viscarra).
} 
sem abrir precedentes para a contestação. O papel relegado à sociedade é o de expectadora; no máximo, de indivíduos aguardando serem chamados, mas nunca tomando a frente da situação.

Nesse sentido, uma autora cuja contribuição é significativa é Carole Pateman. Em seu livro Participação e teoria democrática (1992), ela destaca o papel educativo que a participação política pode desempenhar. Segundo seus estudos sobre o caso da antiga Iugoslávia, a autora constatou que a participação dotaria os cidadãos das habilidades necessárias para uma maior compreensão da participação (seu efeito pedagógico). Apoiando-se nos estudos de Almond e Verba ela destaca, ainda, a incidência direta produzida pela participação sobre a cultura política, aumentando o senso de eficácia de quem participa. Segundo Pateman:

As pessoas com senso de eficácia política têm mais probabilidade de participar da política do que aquelas que carecem desse sentimento, e se descobriu também que subjacente ao senso de eficácia política está uma sensação geral de eficiência pessoal, que envolve autoconfiança na relação do sujeito com o mundo (PATEMAN, 1992, p. 66).

Tal incidência, quando gerada em níveis locais, causaria, com o tempo, resultados em esferas mais distantes e abstratas da atividade política, tendo um impacto positivo no sistema em seu conjunto e em toda a sociedade, a partir do caráter pedagógico da participação.

Porém, quando se fala em participação política é importante ressaltar que esta pode ocorrer de diferentes formas, o que permite indagar sobre a natureza de seus efeitos. Lúcia Avelar (AVELAR e CINTRA, 2007) problematiza o conceito a partir de Pizzorno (1966), dividindo-o em três canais e duas formas distintas de participação. O canal eleitoral(1), abarcando as atividades ligadas aos partidos políticos e às eleições, de forma a se concentrar na relação direta entre sociedade e Estado. Os canais corporativos (2), referentes à representação de interesses privados e/ou profissionais dentro do Estado $^{5}$ e, por fim, o canal organizacional (3), abrangendo atividades que ocorrem em espaços não institucionalizados, tendo como exemplo a ação de movimentos sociais. Já as formas de participação seriam divididas de acordo com os métodos utilizados. A chamada participação convencional estaria caracterizada pela utilização de meios institucionais, autorizada ou regulada por leis, como, por exemplo: votar em eleições, militância partidária, filiação partidária, entre outras (geralmente ligadas aos canais eleitoral e corporativo). A forma de participação não-convencional se define pela utilização de meios extra-institucionais de atuação, frequentemente indo de encontro às regras estabelecidas, como greves, ocupações, obstrução de vias

\footnotetext{
${ }^{5}$ Sobre o corporativismo ver Lehmbruch (1982).
} 
públicas, etc. (não necessariamente correspondem aos canais organizacionais, embora possam ser comumente ligadas a estes).

Para além da classificação apresentada por Avelar (AVELAR e CINTRA, 2007), estamos agregando a este estudo uma terceira forma de participação, aqui denominada participação comunitária. Esta corresponde a formas de atuação que ocorrem em movimentos de bairros e associações comunitárias, e também em algumas ONGs de atuação de base ${ }^{6}$. Vale destacar que desde a década de 1980 tais associações tiveram um aumento significativo, e foi dessa massa mobilizada que se originou o Orçamento Participativo de Porto Alegre, no final daquela década. A participação comunitária, embora não ocorra por dentro de canais institucionais e diretamente vinculados ao Estado, não adota, normalmente, métodos de ação caracterizados pelo enfrentamento direto à ordem.

Retomando a discussão apresentada no início deste trabalho, o que se tem observado recentemente é o crescente distanciamento das pessoas da atividade política. Tal comportamento está ligado à insatisfação das pessoas com o desempenho de instituições políticas e de governantes na resolução de seus problemas mais imediatos (PNUD, 2004). A coexistência de regimes democráticos com altos índices de desigualdade social tem produzido muitos pontos negativos para as jovens democracias latino-americanas. Salvo irrupções momentâneas e de variados graus de intensidade de protestos e rebeliões sociais presenciados em alguns países da América Latina nos últimos $\operatorname{anos}^{7}$, o que tem predominado é a apatia política e a insatisfação com as instituições e governantes frente ao descalabro social da região (BAQUERO, 2001).

Como parte de uma pesquisa realizada em três cidades da América do Sul (Porto Alegre, Montevidéu e Santiago) ${ }^{8}$, este artigo se debruça sobre os dados empíricos obtidos por meio da survey realizado em Porto Alegre. Ao

\footnotetext{
${ }^{6}$ ONGs de atuação de base são aqui entendidas como as organizações cujo centro envolve a mobilização e o relacionamento com a população que pretende representar ou incidir, excluindose aquelas organizações que se distanciam das comunidades sociais.

7 Não se pode falar de plena apatia política em razão de elementos como protestos e rebeliões sociais como o Argentinazo (2001), a Guerra da água (Bolívia, 2000), os sucessivos protestos indígenas no Equador, todos levando à queda de presidentes, além de diversos outros fenômenos não menos importantes envolvendo ações de claro repúdio a governos democraticamente eleitos, instituições políticas e procedimentos relativos à democracia.

8 "Capital social e desenvolvimento sustentável na promoção da cidadania e melhoria da qualidade de vida: estudo comparado entre cidades do Brasil, Chile e Uruguai". O projeto foi dirigido pelo prof. Dr. Marcello Baquero (NUPESAL/UFRGS) e financiado pelo CNPq a partir do edital PROSUL, destinado a atividades de cooperação científica entre países da América do Sul. A equipe de pesquisa foi composta de pesquisadores brasileiros, chilenos e uruguaios. O cálculo amostral, a sistematização e montagem de banco de dados e a elaboração dos primeiros tratamentos e análises estatísticas ficaram a cabo do então bolsista de iniciação científica (PIBIC) Douglas Santos Alves.
} 
confrontar as questões acima com os resultados deste estudo, à época ainda parcial, os resultados foram elucidativos ${ }^{9}$.

Tal como havia sido sugerido, os índices sociais acumulados durante a era neoliberal poderiam comprometer a legitimidade do Estado frente aos cidadãos. Assim, devemos avaliar a percepção dos porto-alegrenses sobre a eficiência estatal na resolução efetiva das demandas sociais. Esse trabalho priorizou três variáveis para avaliar a insatisfação da população de Porto Alegre: (a) credibilidade da aplicação dos recursos públicos, (b) qualidade dos serviços prestados e (c) avaliação do valor pago em impostos. Para tanto foi construído um índice que permitiu tratar o conjunto dos serviços públicos prestados em nível federal, estadual e municipal ${ }^{10}$.

Sobre a credibilidade da aplicação de recursos públicos (a), 85,1\% dos entrevistados discordam totalmente ou em parte da eficiência do Estado. Ressaltando esse fato, $81,2 \%$ dos habitantes afirmam que a qualidade dos serviços públicos prestados (b) no município de Porto Alegre é ruim ou mais ou menos. Somado a isso, $84,4 \%$ afirmam pagar um valor muito alto em impostos (c) pelos serviços prestados. Assim, é possível concluir que a maioria dos cidadãos dessa cidade está bastante insatisfeita com a política de serviços prestados pelos governos, sejam eles municipal, estadual ou federal.

Tal insatisfação parece repercutir na avaliação sobre as três instâncias do poder executivo ${ }^{11}$. A Tabela 1 aponta para uma avaliação positiva (Muito Boa e Boa, somadas) muito baixa, sendo um quarto para governador e prefeito e pouco mais de um terço para presidente.

Tabela 1 - Avaliação dos governantes (\%)

\begin{tabular}{l|c|c|c}
\hline & Presidente & Governador & Prefeito \\
\hline Muito bom ou bom & 36,9 & 25,2 & 25,1 \\
\hline Regular & 43,8 & 51,4 & 51,4 \\
\hline Ruim ou péssimo & 19,4 & 23,4 & 23,4 \\
\hline
\end{tabular}

Fonte: Pesquisa NUPESAL (2005).

Tais dados são reforçados pela avaliação acerca do mau funcionamento da democracia, na qual $81,2 \%$ da população se diz insatisfeita ou pouco satisfeita com seu desempenho.

Assim, percebemos que os baixos índices sociais da região, indicados por meio do cálculo negativo da população sobre os serviços públicos

\footnotetext{
${ }^{9}$ Para maiores detalhes sobre os procedimentos metodológicos, cálculo dos índices e amostragem ver Baquero (2007).

${ }^{10}$ Os percentuais que seguem são referentes ao índice calculado com base nas variáveis que medem a avaliação dos seguintes serviços: saúde, educação, esporte/lazer/cultura, transporte, segurança pública, saneamento básico, habitação e telefonia, a partir das categorias Boa, Mais ou Menos e Ruim.

${ }^{11} \mathrm{Na}$ época da pesquisa os governantes em vigor eram Luís Inácio Lula da Silva (PT) como presidente, Germano Rigotto (PMDB) como governador e José Fogaça como prefeito (PPS-PTB).
} 
prestados, parecem estar ligados à avaliação dos governantes e do desempenho da democracia. Em verdade, a população da capital gaúcha está bastante insatisfeita com 0 atendimento que 0 Estado presta às suas necessidades mais imediatas.

Tal ineficiência e insatisfação se refletem nos baixos índices de confiança (Tabela 2). É interessante observar que três instituições ficam abaixo da linha dos $10 \%$ de confiança recebida pela população: o Congresso Nacional, $7 \%$, os Deputados Estaduais, $7 \%$ e os Partidos Políticos, $6 \%$. Com percentuais de confiança que vão até $25 \%$ da população ficam: o Presidente, $10 \%$, o Governador, $11 \%$, os Vereadores, $11 \%$, o Prefeito, $12 \%$, a Polícia, $14 \%$ e o Judiciário, $25 \%$.

Esse fato é bastante preocupante uma vez que o percentual de pessoas que confiam nas instituições listadas, muitas delas essenciais para o regime democrático, não passam de um quarto da população de Porto Alegre. O maior índice de confiança é expresso na família, $87 \%$, seguido pela igreja, $40 \%$, pessoas, $32 \%$, vizinhos, $30 \%$ e associações comunitárias, $27 \%$. Á exceção da família, nenhuma outra variável alcança confiança de mais da metade da população.

Tabela 2 - Confiança nas instituições (\%)

\begin{tabular}{l|c|c}
\hline & Confia muito & Confia pouco/ não confia \\
\hline Congresso Nacional & 7 & 93 \\
\hline Presidente/Ministros & 10 & 90 \\
\hline Deputados Estaduais & 7 & 93 \\
\hline Governador/secretários & 11 & 89 \\
\hline Vereadores & 11 & 89 \\
\hline Prefeito & 12 & 88 \\
\hline Judiciário & 25 & 75 \\
\hline Partidos Políticos & 6 & 94 \\
\hline Polícia & 14 & 86 \\
\hline Igreja & 40 & 60 \\
\hline Família & 87 & 13 \\
\hline Associações Comunitárias & 27 & 73 \\
\hline Vizinhos & 30 & 70 \\
\hline Pessoas & 32 & 66
\end{tabular}

Fonte: Pesquisa NUPESAL (2005).

De um modo geral, estes dados apontam para um cenário bastante preocupante. Porém, esta análise poderia sofrer questionamentos quanto ao seu significado se confrontada com a idéia de que a relação da sociedade com o Estado no Brasil historicamente foi frágil, o que de fato é verdade. Assim, para além dessa análise, é importante tentar perceber a dinâmica dessa relação no período de transição para o regime democrático e no período aberto posteriormente, relativo à sua "consolidação". Nesse sentido, uma 
avaliação longitudinal pode auxiliar a identificar a existência ou não de uma tendência de deterioração dessa relação.

Quando os dados da Tabela 2 são comparados com informações de pesquisas anteriores verifica-se a diminuição da confiança ao longo do tempo em instituições como governo federal, congresso nacional, e partidos políticos $(\text { Gráfico } 1)^{12}$. Aqui fica mais visível a idéia de um distanciamento gradual da política que, com a ressalva de oscilações conjunturais, parece se concentrar no período que se abre no final dos anos 1980 e início da década seguinte. O que chama a atenção é o fato de que a tendência de queda, que poderia se justificar nos anos do regime autoritário $\left(1964-1985^{13}\right)$, persiste após o fim da ditadura militar.

\footnotetext{
12 Os dados dos Gráficos 1, 2 e 3 são referentes às pesquisas de opinião e participação política realizados pelo NUPERGS. Os dos 1968 e 1976 são relativos às cidades de Ijuí e Caxias do Sul, respectivamente. Estas cidades foram inseridas na análise segundo o critério de equivalência funcional por suas características semelhantes às de Porto Alegre devido à impossibilidade de realização do estudo na Capital na época, fruto do contexto do regime autoritário. A organização e sistematização destes dados foi realizada por Douglas Santos Alves, bolsista de iniciação científica na época.

${ }^{13}$ As pesquisas entre 1964 e 1985 foram realizadas durante o regime militar brasileiro. Todavia, como o entrevistado não precisava ser identificado, e as entrevistas não eram gravadas o risco dos respondentes estarem sendo influenciados pelo contexto político da época era mínimo.
} 


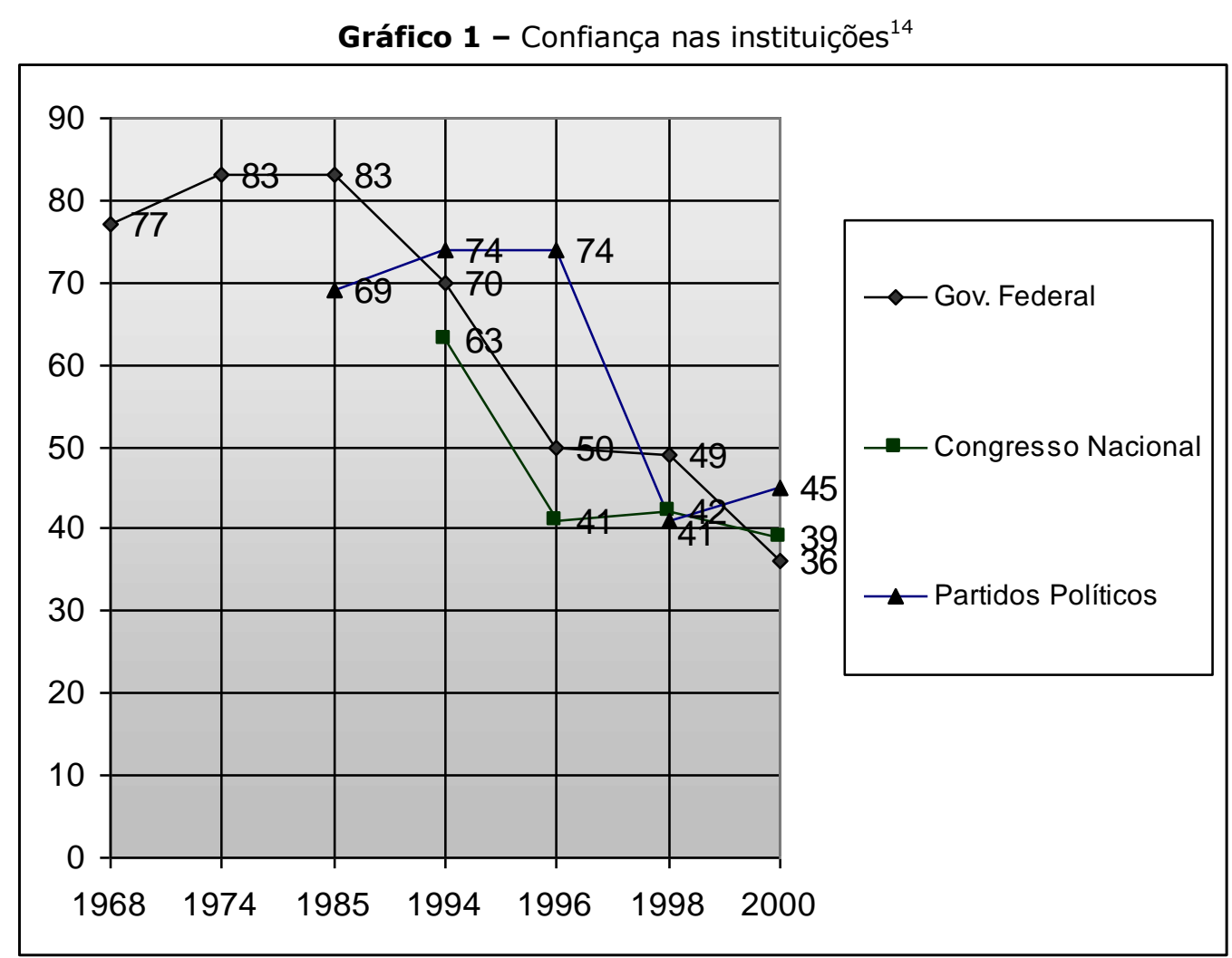

Fonte: UFRGS - NUPERGS (1968-1985); NUPESAL (1994-2000).

Considerando a relação existente entre confiança e participação política, os dados apresentados podem auxiliar na compreensão dos índices de participação dos entrevistados.

Pesquisas de comportamento eleitoral realizadas desde a década de 1960 pelo NUPERGS (UFRGS) vêm medindo o nível de participação entre os gaúchos. O Gráfico 2 mostra a evolução do comportamento político dos gaúchos com relação a essa forma de participação de acordo com as variáveis mais pertinentes às características do contexto brasileiro no respectivo período histórico.

O que se constata é a persistência de uma baixa participação política em atividades eleitorais (canal eleitoral) como em comícios, carreatas, contribuição financeira a candidaturas e partidos, voluntariado, utilização de propaganda em casa, no carro ou no trabalho, presença em reuniões e/ou debates em centros comunitários se mantêm relativamente estáveis com

\footnotetext{
${ }^{14}$ A amostra para esses anos foi de: 225 para 1968, 367 para 1974, 483 para 1985, 300 para 1996, 248 para 1998 e 532 para 2000.
} 
pequenas oscilações conjunturais. O único indicador com significativa variação é o da audiência ao horário eleitoral gratuito, que após uma significativa audiência nos anos 1990, vem declinando e aproximando-se do restante dos indicadores. É interessante observar que a participação neste tipo de atividade esteve repleta de restrições fruto do regime autoritário. Mesmo assim, os baixos índices também persistiram e se aprofundaram após a abertura política.

Desse modo é possível falar de um distanciamento estrutural das formas institucionais de atuação (participação convencional). Considerando que o conjunto de variáveis refere-se ao processo eleitoral, e que os percentuais declinam principalmente na década de 1990, portanto durante 0 período de consolidação democrática, torna-se necessário questionar a eficácia da institucionalização dos procedimentos democráticos, em especial no que se refere ao processo de escolha dos governantes. 
Gráfico 2 - Participação Política 1968-2004 ${ }^{15}$

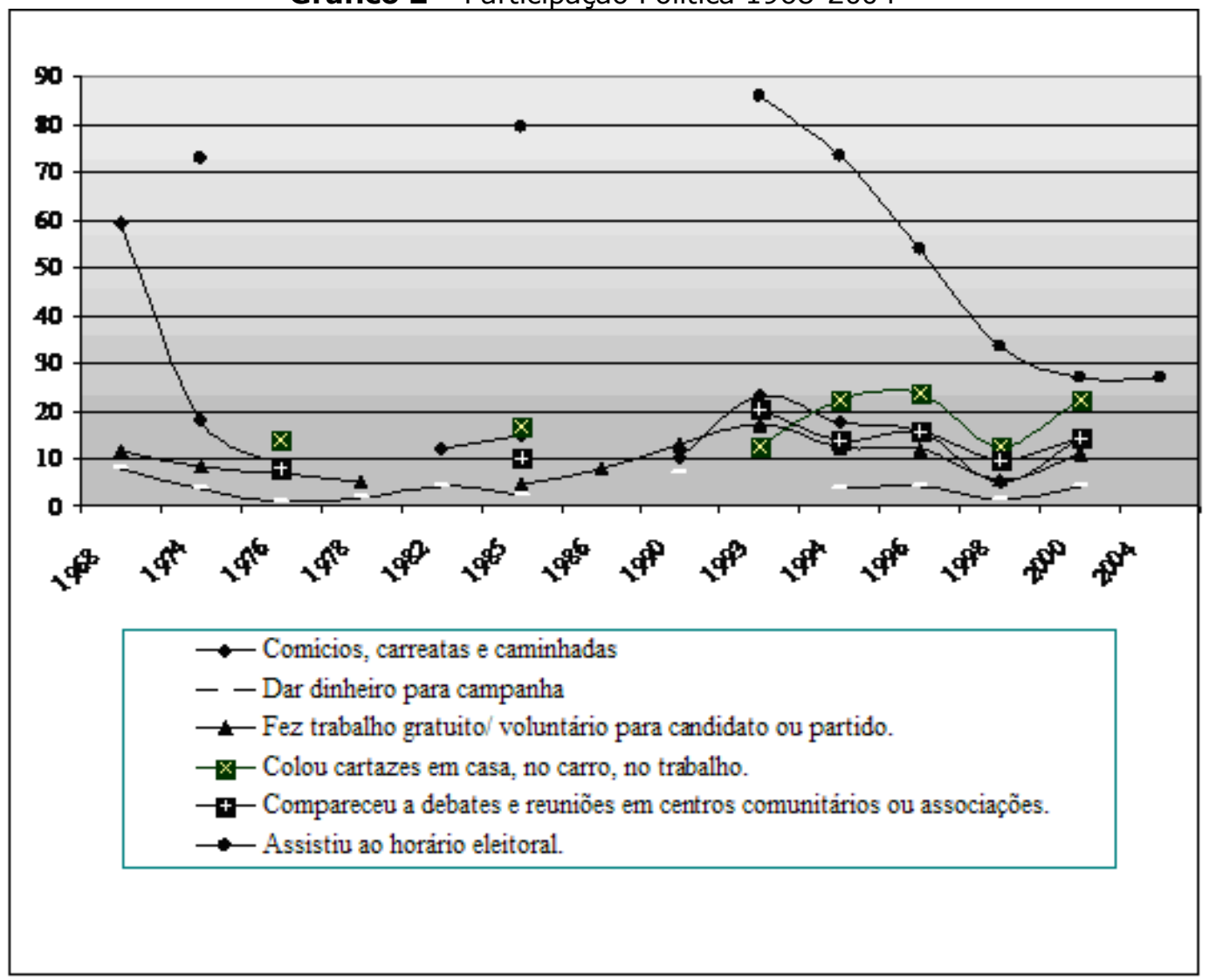

Fonte: UFRGS - NUPERGS (1968-1993); NUPESAL (1994-2004).

Se por um lado parece existir um afastamento das pessoas da política institucional, por outro supõe-se que tal fato favoreça o deslocamento das pessoas dos canais formais para as associações de caráter comunitário. Um dos elementos que reforçam essa idéia é a não vinculação de tais associações diretamente às instituições do Estado. Entretanto, o Gráfico 3 mostra exatamente o contrário. O que se constata é um significativo declínio da participação em associações dessa natureza nas últimas duas décadas. 0 esvaziamento das formas convencionais de participação não produziu o fortalecimento do associativismo. Alguns autores identificam uma forte tradição associativa em Porto Alegre (AVRITZER e NAVARRO, 2003), manifestada, até fins dos anos de 1980, na constituição de associações de

\footnotetext{
${ }^{15}$ A amostra para esses anos foi de: 225 para 1968, 367 para 1974, 883 para 1976, 600 para 1982, 483 para 1985, 600 para 1990, 609 para 1994, 300 para 1996, 248 para 1998, 532 para 2000 e 635 para 2004.
} 
moradores com caráter mais reivindicativo. Esta tradição teria servido de lastro para a criação e consolidação do Orçamento Participativo nesta cidade. Contudo, no período que vai de 1976 a 1998 e abrange a constituição e consolidação do OP, observa-se um decréscimo significativo na participação dessas associações.

GRÁFICO 3 - Participa de movimento associativo 1974-2003

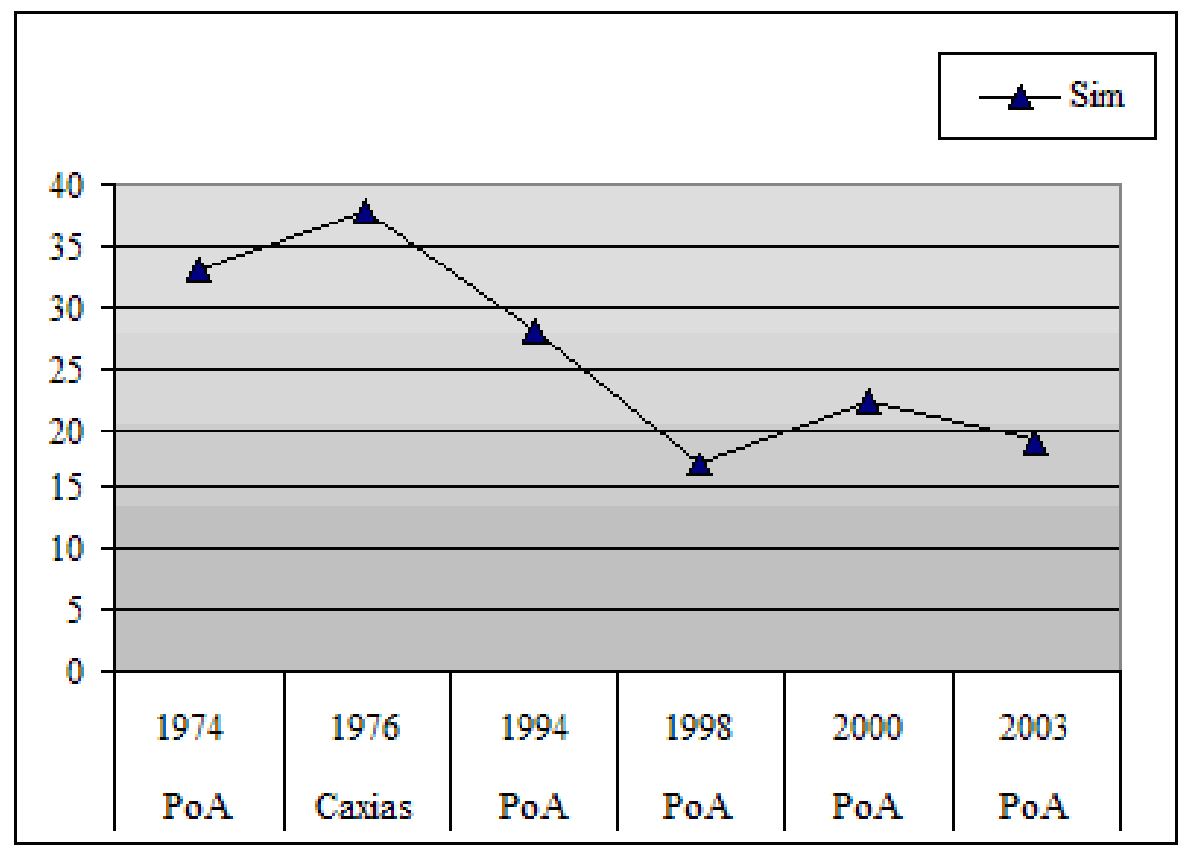

Fonte: UFRGS - NUPERGS (1974- 1976); NUPESAL (1994-2003).

O processo de consolidação de procedimentos e instituições democráticas acontece de forma mais ou menos paralela com a implementação das políticas neoliberais. As consequências dessas políticas são constatadas pela elevada insatisfação da população com o papel desempenhado pelo Estado a partir dos indicadores aqui analisados. Em geral, as pessoas crêem que pagam muito por muito pouco, ou seja, cumprem com sua obrigação numa relação desigual, na qual o Estado se ausenta de seu papel em favor do mercado. Tal insatisfação tem atingido os diferentes níveis de governo na forma de uma má avaliação de seu desempenho. É sobre ele que recai a expectativa da resolução dos problemas sociais, ainda mais em sociedades onde os executivos detêm tanto poder sob consentimento da população (O'DONNELL, 1991). Porém, não são somente os governantes os atingidos pelos desdobramentos da insatisfação. O conjunto das instituições ligadas à democracia sofre de uma taxa muito alta de desconfiança. A população parece ser indiferente ou mesmo antipática à institucionalidade 
como um todo. Além desta, as relações sociais mais amplas também estão afetadas. A confiança em associações locais, sindicatos e movimentos sociais entre outros, bem como a própria confiança interpessoal, estão bastante baixas. Esse quadro evidencia um reduzido estoque de capital social, uma débil capacidade associativa e a constituição de identidades sociais fragmentárias.

Nesse cenário é possível sugerir um baixo grau de comprometimento da sociedade com o Estado e suas instituições. A idéia de que a democracia se fortalece a partir da garantia de procedimentos formais de escolha de governantes e de tomada de decisões fica fortemente abalada. Se não há um comprometimento da sociedade com tais procedimentos, dificilmente haverá um comportamento fiscalizador da coisa pública, o que cria terreno fértil para os frequentes desmandos do Estado, corrupção e a permanência de práticas como o clientelismo, o personalismo entre outras. É importante, por fim, compreender que essa situação é resultado de um processo. A dinâmica da relação entre sociedade e Estado no último período aponta para um enfraquecimento gradual. As expectativas surgidas com a democracia parecem não ter sido atendidas.

Frente a este cenário o debate apresentado sobre participação ganha relevo. O ponto de partida é: como a satisfação, a confiança e os baixos indicadores de participação política (que vem de um gradativo declínio ao longo dos últimos anos) se configuram. Vale lembrar que, como já mostrado acima, tanto os denominados canais eleitorais, diretamente ligados ao Estado e aos partidos políticos, quanto os organizacionais, referentes a movimentos associativos em geral, sofrem de um profundo descrédito por parte da população.

Por um lado, a baixa participação parece estar associada aos elevados níveis de insatisfação e desconfiança. Por outro, as práticas participativas guardam significativas possibilidades de construção de capital social.

Tais tendências assumem maior relevância quando examinados os dados de 2005, que confirmam a sua manutenção. Os dados da Tabela 3 mostram os resultados de um índice de participação criado com base em treze variáveis distintas: partidos políticos, reuniões políticas, comícios, associações comunitárias, associações religiosas, associações sindicais, conselhos populares, ONGs, orçamento participativo, abaixo-assinados, manifestações ou protestos, ocupações de terrenos ou prédios públicos.

Por meio de análise fatorial essas variáveis foram agrupadas nas três categorias de participação já mencionadas (convencional, não convencional e comunitária). A partir disso, criou-se uma escala de três níveis de participação: baixa, média e alta, com base no índice calculado para cada uma ${ }^{16}$.

${ }^{16}$ O Índice Participação Política foi construído a partir das variáveis listadas. As respostas receberam a seguinte pontuação: 0 (zero) para "Não", 1 (um) para "Já participou" e 2 (dois) para 
Tabela 3 - Participação Política

\begin{tabular}{l|c|c|c}
\hline & Convencional \% & Não Convencional \% & Comunitária \% \\
\hline Baixa & 78,6 & 81,2 & 83,6 \\
\hline Média & 17,8 & 16,6 & 13,8 \\
\hline Alta & 3,6 & 2,2 & 2,6 \\
\hline \multicolumn{4}{|c}{$\mathrm{n}=510$}
\end{tabular}

Fonte: Pesquisa NUPESAL (2005).

Esses indicadores respaldam os dados anteriores, demonstrando que 0 percentual de pessoas com baixo grau de comportamento participativo passa dos três quartos em todas as formas de participação: convencional $(78,6)$, não convencional $(81,2)$ e na comunitária $(83,6 \%)$.

No entanto, é necessário avaliar o perfil das pessoas que participam. Como a taxa de participação (média/alta) se distribui de acordo com variáveis como renda per capita, escolaridade, faixa etária e gênero ${ }^{17}$.

Ao analisar a influência do gênero sobre diferentes formas de participação, o resultado encontrado é bastante instigante. Nas três categorias de participação a presença das mulheres é superior à dos homens. Sendo que essa diferença aumenta gradativamente da convencional $(3,7 \%)$ para a não convencional $(7,1 \%)$ até atingir o valor mais significativo na comunitária $(8,5 \%)$.

Tabela 4 - Gênero e Índice de Participação média/alta ${ }^{18}$

\begin{tabular}{l|c|c|c}
\hline & Convencional & Não convencional & Comunitária \\
\hline Masculino & 19,3 & 14,8 & 11,6 \\
\hline Feminino & 23 & 21,9 & 20,1 \\
\hline
\end{tabular}

Fonte: Pesquisa NUPESAL (2005).

No caso da influência da variável idade, distribuída por faixas etárias, vale destacar que tanto na forma convencional quanto na não convencional, o grupo predominante se encontra entre os 30 e 49 anos de idade. Já na comunitária o que se verifica é uma tendência à queda de acordo com o avanço da idade.

\footnotetext{
"Sim". A soma dessas variáveis variou em um índice de 0 a 18 pontos para os dados de Porto Alegre. O índice foi recodificado em 3 categorias: Baixa, Média, Alta. As respostas "NR" não foram consideradas. Onde 0 a não participação e 1 participação no item questionado ao entrevistado.

17 Essas variáveis foram escolhidas com base nos resultados obtidos a partir de um teste de associação simples (chi-quadrado) que nos três casos permitiu aceitar nossa hipótese de trabalho (para 95\% de probabilidade de ocorrência, segundo a metodologia usada na coleta dos dados).

$18 \chi^{2}=$ Participação convencional 0,009 ; participação não convencional 0,036 ; participação comunitária 0,043.
} 
A SITUAÇÃO DAS AMÉRICAS:

DEMOCRACIA, CAPITAL SOCIAL E EMPODERAMENTO

Tabela 5 - Faixa Etária e Participação média/alta ${ }^{19}$

\begin{tabular}{l|c|c|c}
\hline \multicolumn{1}{c|}{ Faixa Etária } & Convencional & Não convencional & Comunitária \\
\hline $16-29$ & 21,9 & 17,8 & 18,4 \\
\hline $30-49$ & 23,4 & 19,8 & 16,6 \\
\hline+ de 50 & 15,9 & 17,8 & 13,1 \\
\hline
\end{tabular}

Fonte: Pesquisa NUPESAL (2005).

Em relação à renda per capita na participação convencional não há grande variação nas três primeiras faixas de renda, somente uma diminuição significativa a partir dos 11 salários mínimos. Já na participação não convencional pode-se observar uma preponderância na faixa dos 6 até 10 SMs, com 29,2\%; e 19,5\% na faixa anterior, que representa renda de 1 até 5 SMs na participação comunitária.

Tabela 6 - Participação e renda per capita ${ }^{20}$

\begin{tabular}{l|c|c|c}
\hline \multicolumn{1}{c|}{ Faixa de renda per capita } & Convencional & Não convencional & Comunitária \\
\hline Até $1 \mathrm{sm}$ & 21,9 & 21,7 & 13,2 \\
\hline 1 à $5 \mathrm{sm}$ & 20,5 & 17,4 & 19,5 \\
\hline 6 à $10 \mathrm{sm}$ & 20,8 & 29,2 & 4,2 \\
\hline 11 à 20 & 12,5 & 12,5 & - \\
\hline Mais de 20 sm & - & - &
\end{tabular}

Fonte: Pesquisa NUPESAL (2005).

Quanto à participação e escolaridade (Tabela 7) é interessante observar que os maiores índices de participação estão concentrados a partir dos que estão cursando o ensino médio. Chama a atenção o fato de que entre o médio e o superior, a participação convencional e comunitária aumentam, enquanto que a participação não convencional diminui.

$19 \chi^{2}=$ Participação convencional 0,025 ; participação não convencional 0,008 , participação comunitária 0,024.

${ }_{20}^{2} \chi^{2}=$ Participação convencional 0,019 ; participação não convencional 0,018 , participação comunitária 0,083. 
A SITUAÇÃO DAS AMÉRICAS:

DEMOCRACIA, CAPITAL SOCIAL E EMPODERAMENTO

Tabela 7 - Participação e escolaridade ${ }^{21}$

\begin{tabular}{|c|c|c|c|}
\hline Escolaridade por grau & Convencional & Não convencional & Comunitária \\
\hline Fundamental incompleto & 19,7 & 19 & 16,3 \\
\hline Fundamental completo & 18,2 & 14,7 & 11,8 \\
\hline Médio incompleto & 26,5 & 24,5 & 20,4 \\
\hline Médio completo & 22,7 & 20,2 & 17,8 \\
\hline Superior incompleto & 23,7 & 12,1 & 22 \\
\hline Superior ou mais & 19,1 & 19,1 & 10,1 \\
\hline
\end{tabular}

Além da análise das formas de participação cruzadas por variáveis demográficas, é interessante fazer uma avaliação da sua relação com variáveis de eficácia política, na tentativa de compreender como se interinfluenciam.

Gráfico 4 - Índice de participação e satisfação

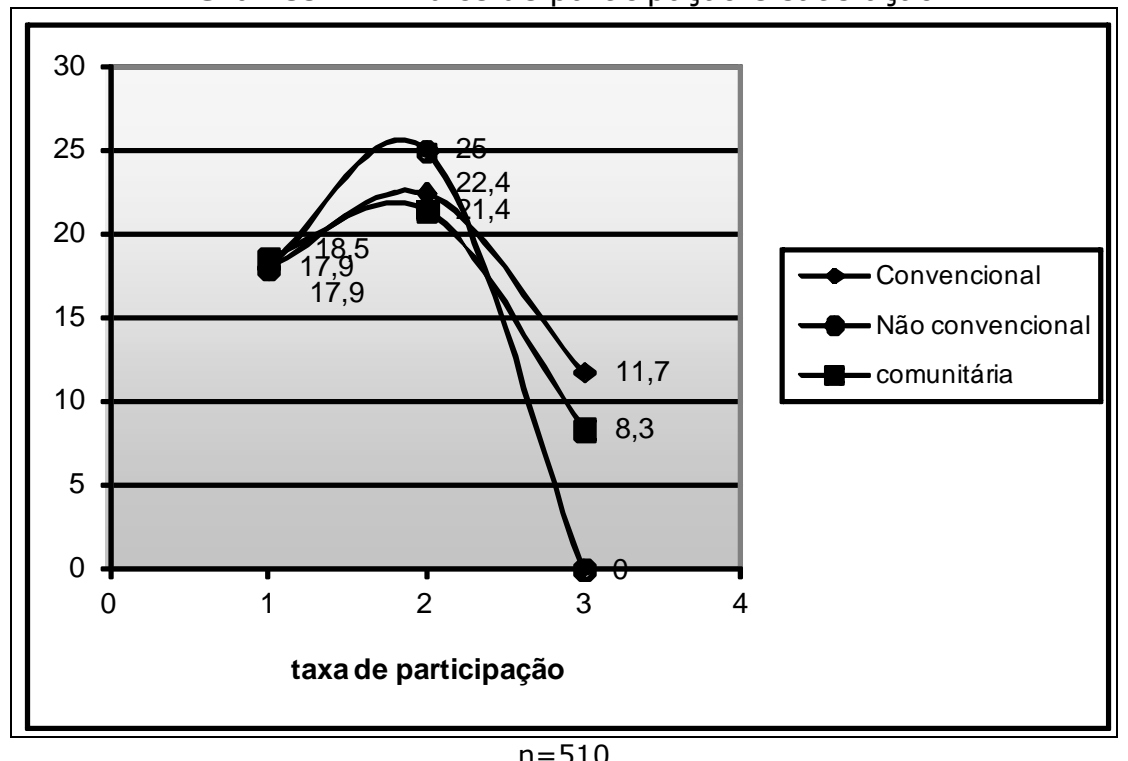

Fonte: Pesquisa NUPESAL (2005).

Nesse sentido, o Gráfico 4 mostra que a evolução da taxa de participação das pessoas nas três categorias aqui propostas (convencional, não convencional e comunitária) é acompanhado de uma ligeira ascensão do grau de satisfação com a democracia no nível intermediário, porém sofre uma brusca queda quando atinge o nível mais alto. A queda menos significativa é a da participação convencional $(12 \%)$, possivelmente porque a atuação por

$21 \chi^{2}=$ Participação convencional 0,000 ; participação não convencional 0,000 ; participação comunitária 0,094. 
dentro dos espaços oferecidos pelo sistema dependem de um mínimo de legitimidade e apoio ao regime e suas instituições. Já a mais saliente é a da participação não convencional $(0 \%)$; fato que se explica pelas características próprias dessa categoria de participação, ou seja, a busca de espaços extrainstitucionais para a atuação política é coerente com uma baixíssima satisfação com o funcionamento da democracia. Num patamar intermediário (8\%), está a participação comunitária. Ao contrário das formas não convencionais, esse tipo de participação não tem como lógica de atuação o enfrentamento direto com governos e instituições; contudo, não recorre aos espaços e canais disponibilizados pelo Estado do mesmo modo que a convencional.

Gráfico 5 - Importância da participação nas decisões do Governo

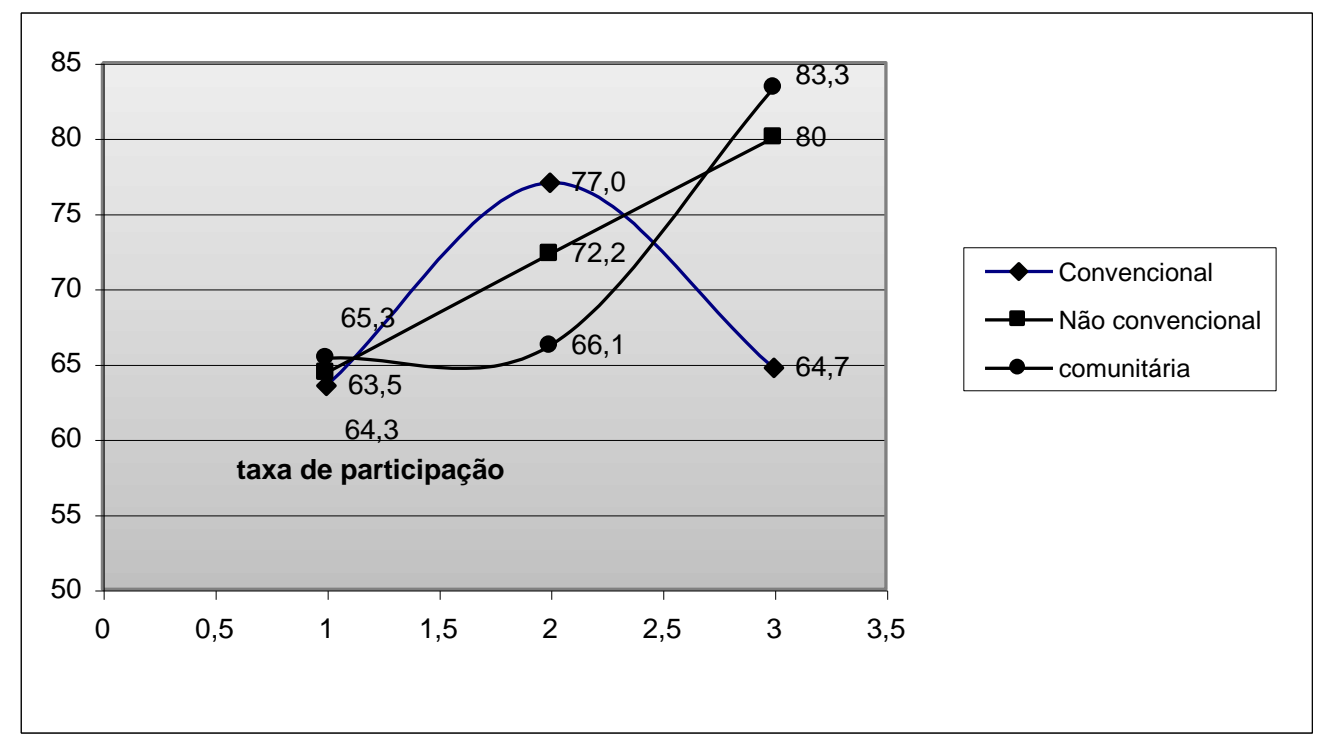

$\mathrm{n}=510$

Fonte: Pesquisa NUPESAL (2005).

Ao medir a importância que as pessoas atribuem à participação nas decisões tomadas pelo governo de acordo com a evolução da taxa de participação, é possível observar um declínio da forma convencional e uma ascensão das outras duas formas de participação, conforme o Gráfico 5. Tanto as pessoas que atuam dentro da categoria comunitária como da convencional se consideram mais influentes nas decisões políticas do governo conforme aumenta sua taxa de participação. Contudo, a curva da linha referente à forma convencional de participação vai num sentido oposto. $O$ senso de eficácia política decai com o aumento da participação. A principal característica dessa modalidade é limitar-se aos espaços institucionalizados, portanto, parece coerente que as decisões do governo fiquem a cargo do 
próprio governo, enquanto que os indivíduos altamente participativos dessa modalidade se restrinjam a atuar dentro dos espaços a eles concedidos. Essa queda é compreensível com base nos dados referente à falta de confiança nas instituições (Tabela 2 e 3).

$$
* * *
$$

Os dados aqui analisados sugerem haver uma relação entre capital social, participação e satisfação. É possível constatar durante os últimos anos, período de implementação da democracia no país, um decréscimo significativo no processo de participação. O mesmo período é marcado por transformações que atingem diretamente a vida das pessoas, e tem como resultado a intensificação da crise social. Dessa maneira fica explícito tanto a insatisfação com o desempenho do sistema democrático, como a baixa confiança depositada em suas instituições. A institucionalização da lógica do "salve-se quem puder" (BAQUERO, 2009), do individualismo exacerbado e da fragmentação dos laços sociais, indica um baixo índice de capital social, ainda que a confiança interpessoal seja um pouco maior que a depositada nas instituições. O rechaço das instituições do regime é acompanhado pela avaliação da ineficiência do Estado na solução de problemas sociais. Com efeito "[...] os cidadãos não veem no Estado a resposta aos seus problemas materiais mais imediatos [...]" (ALVES et. al., 2005), não reconhecem as alternativas oferecidas pelo regime, se afastando dos canais disponibilizados para sua atuação. Assim não reconhecendo à ação coletiva institucional em geral.

A participação, neste trabalho desmembra-se em três formas distintas, sofrendo os reflexos do baixo nível de capital social, bastante reduzido nas três categorias estudadas. Da mesma forma, se relaciona de maneira distinta com a cultura política e a satisfação.

Em vista disso, os diferentes graus de satisfação tendem a se relacionar com a democracia e a se associar às diferentes modalidades de participação, com resultados distintos em cada uma, variando de acordo com suas características inerentes. Também o sentimento de eficácia na influência das decisões do governo está associado de forma distinta a essas categorias participativas, mais uma vez variando de acordo com as características de cada uma delas. O elemento que parece ser determinante dessa variação é o tipo de relação que cada categoria estabelece com o Estado. Uma análise mais aprofundada deste tema demandaria um esforço mais específico, agregando técnicas de investigação qualitativas. Portanto, os resultados aparecem como um campo fértil para a investigação social.

Douglas Santos Alves é graduado em Ciências Sociais pela Universidade Federal do Rio Grande do Sul e Mestre em Ciência Política pela Universidade Estadual de Campinas. Atualmente é Professor de Ciência Política na 
Universidade Federal da Fronteira Sul.

E-mail: douglasrev@yahoo.com.br

Simone Piletti Viscarra é graduada em Ciências Sociais pela Universidade Federal do Rio Grande do Sul e Mestre em Ciência Política pela mesma instituição. Atualmente é aluna de doutorado em Ciência Política na UFRGS.

E-mail: simoneviscarra@gmail.com

\section{Referências}

ALVES, Douglas Santos et. al. Bases de um novo contrato social? Impostos e Orçamento Participativo em Porto Alegre. Opinião Pública, Campinas, v. 11, n. 1, p. 94-127, mar. 2005.

AVELAR, Lúcia; CINTRA, Antônio Octávio. Participação Política. In: AVELAR, Lucia; CINTRA, Antonio Octávio (Org.). Sistema Político Brasileiro - Uma Introdução. São Paulo/Rio de Janeiro: UNESP/Konrad-Adenauer, 2007. p. 223-237.

AVRITZER, Leonardo. Um desenho institucional para o novo associativismo. Lua Nova, São Paulo, v. 1, n. 39, p.149-174, 1997.

AVRITZER, Leonardo; NAVARRO, Zander. A inovação democrática no Brasil: o orçamento participativo. São Paulo: Cortez, 2003.

BAQUERO, Marcello. Cultura política participativa e desconsolidação democrática: reflexões sobre o Brasil contemporâneo. São Paulo em Perspectiva, São Paulo, v. 15, n. 4, p. 98-104, out.-dec. 2001.

- Construindo uma outra sociedade: o capital social na estruturação de uma cultura política participativa no Brasil. Revista de Sociologia e Política, Curitiba, n. 21, p. 83-108, nov. 2003.

UFRGS, 2007.

- Democracia e Desigualdades na América Latina. Porto Alegre:

BAQUERO, Marcello; BAQUERO, Rute V. Cultura política, capital social e empoderamento na construção democrática da América Latina. In: LASA International Congress Of The Latin American Studies Association. Rio de Janeiro, 28., 2009.

COLEMAN, James S. Foundations of Social Theory. Cambridge: Harvard University Press, 1990. 
DURLAUF, Steve. Social Capital. 2004. Disponível em: <http://www.ssc.wisc.edu/econ/Durlauf>. Acesso em: 11 nov. 2005.

FUKUYAMA, Francis. Confiança: as virtudes sociais e criação de prosperidade. Rio de Janeiro: Rocco, 1996.

HUNTINGTON, Samuel P. Political order in changing societies. New Haven: University Press, 1968.

LEHMBRUCH, Gerhard. Neo-Corporatism in Comparative Perspective. In: LEHMBRUCH, Gerhard; SCHMITTER, Phillippe C. Patterns of Corporatist PolicyMaking. London: Sage Publications, 1982. p. 1-28.

O'DONNELL, Guillermo. Democracia delegativa? Novos Estudos CEBRAP, São Paulo, s/v., n. 31, p. 25-40, out. 1991.

PATEMAN, Carole. Participação e teoria democrática. Rio de Janeiro: Paz e Terra, 1992.

PIZZORNO, Alessandro. Introduzione allo studio della participazione política. Quaderni di Sociologia, v.15, n.3-4, p. 288-309, giug.-dic. 1966.

PNUD. A democracia na América Latina: Rumo a uma democracia de cidadãs e cidadãos. São Paulo: LM\&X, 2004.

PUTNAM, Robert. Making Democracy Work: Civic Traditions in Modern Italy. Princeton: Princeton University Press, 1993.

TOCQUEVILLE, Alexis de. A democracia na América. São Paulo: Edusp, 1977.

Texto recebido em 19/01/2012. Aprovado em 06/04/2012. 